\title{
The Use of Flow-Induced Vibration as An Alternative Resource of New Power Plant in Indonesia
}

\author{
Subekti ${ }^{1,}$, Abdul Hammid ${ }^{1}$, and Adi Surjosatyoe ${ }^{2}$ \\ ${ }^{1}$ Mechanical Engineering, Universitas Mercu Buana, Meruya Selatan, Kembangan, Jakarta Barat, 11650, Indonesia \\ ${ }^{2}$ Mechhanical Engineering, Universitas Indonesia, Kampus UI Depok 16424, Indonesia
}

\begin{abstract}
Considering the current energy crisis in Indonesia which is indicated by the depletion of oil reserve, the government believes that the existing power plants are not adequate to meet the electricity needs of this country. This can be seen clearly with the blackouts in many places in Indonesia. There are two economical methods to generate electricity on a large scale. First is by using hydropower and second is by using heat power. However, this cannot meet the needs of electricity in this country because of the difference in natural conditions in some places in Indonesia. Fluid flow and structure is an interactive system and its interaction is dynamic. This is a coupling system of forces to work on the structure generated by the surrounding fluid. The force of the fluid causes the structure to deform. When the structure is deformed, this means that its orientation to the fluid flow changes, so that, subsequently, the fluid force may change. This condition is called vibration phenomenon caused by flow. This experiment was conducted in Engineering Laboratory of Mercu Buana University Jakarta in 2017. The instrument of this study was the Wind Tunnel. This research aims to find out the flow-induced vibration that was affected by two parameters (flow velocity, the diameter of the kinematic fluid viscosity). These two parameters will get lift force and lift force, thus causing the generator to spin to generate electricity. The result of this research shows that the fluid flow has lift and drag force. The best result was obtained by specimen B velocity of 4.76. It also gave lift displacement of $20 \mathrm{~mm}$. The success of the test depends on the election of spiral spring.
\end{abstract}

\section{Introduction}

The need for electrical energy in Indonesia continuously increases. The electrical energy development is estimated to reach $7,1 \%$ every year with electrification ratio of $60 \%$. The number of power plants in Indonesia is nearly $89,5 \%$ and those use fossil energy [1]. According to the National Energy Policy (KEN), one of the objectivities of KEN is to create the primer energy mix in 2025 by decreasing the natural oil consumption to be less than $20 \%$ and increasing the natural gas consumption to be more than $30 \%$ [2]. The development of alternative energy resources is to decrease the dependence on a single source of energy and using the ones which are environmentally friendly base on the National Energy Policy. The strategic efforts of energy resource include the Intensification, Diversification and Conservation. One of the diversifications and conservation targets is to create the source of electrical energy which eco- friendly. The government of Ministry of Energy and Mineral resources, Directory of General of New Energy and Energy Conservation sets the target to increase the energy source using the renewable energy by $23 \%$ in 2025 (Figure 1). The figure below is the national energy policy based on PP no. 79/2014.

Many intensive studies have been undertaken to create an environmentally friendly source of electrical power generation such as Micro Hydro Power Plant (PLTMH), Solar Power, Wind Power, Biomass Power, and Renewable Power Plants. The few sources of existing eco-friendly power generations, the Renewable Power Plant is one of the most potential alternatives. Renewable marine energy sources are abundant and available in Indonesia because two-thirds of Indonesia area is the ocean. These energy sources include current, tidal, thermal gradient and salinity. One of their utilization is by using the vibration produced by flow or Flow-Induced Vibration. The fluid used in the utilization of flow vibration could be a fluid stream in the form of gas, air or water.

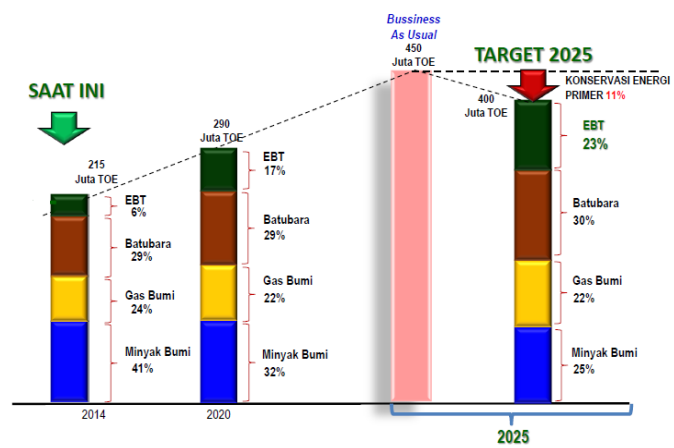

Fig. 1. The national energy policy based on PP. 79/2014 [3]

\footnotetext{
* Corresponding author: subekti@mercubuana.ac.id
} 
The fluid flow and structure are an interactive system and the interaction is dynamic. This is a coupling system of forces acting on structures generated by the surrounding fluid. The force of the fluid causes the structure to deform. When the structure is deformed, this means, there is a change in the orientation of the fluid flow, so that the next time it is possible to change the fluid force. This is called flow-induced vibration. Flooding phenomena are encountered in everyday life, such as wind-blown pastures as shown in Figure 2. If this phenomenon is used as a source of energy, the need for electrical energy will be easily overcome.

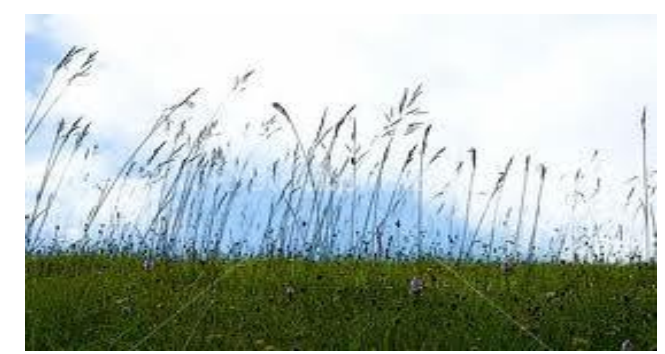

Fig. 2. The vibration of Phenomena because of Flow-Induced Vibration

Due to environmental loads, especially waves and ocean currents, parts of the water-immersed lean structure (riser, tendon, etc.) will experience significant vibrations. It turns out that the vibrations are not only a direct result of primary environmental forces such as waves and currents, but there is a secondary phenomenon that can cause vibrations with a significant frequency.

Some profits of using the flow induced vibration as the new alternative to energy in Indonesia are:

- Now is the right time to consider of vibration generated by the current as a new energy resource considering that $2 / 3$ the region of Indonesia is oceans and rivers.

- Besides, it can be used in the river flow, this technology can be applied in the air-fluid flow.

- The use of vibration generated by the current as an alternative energy resource is very significant to decrease the hydrocarbon and particle emission from the gas exhaust in diesel power plant, etc.

- The technology to be used is the simple one so that people can make their own with a much more economical cost compared with currently existing power plants.

- Some studies estimate that if we can utilize $0.1 \%$ of total ocean energy, we can cover the energy needs of about 15 billion people. The variety of energy that will be used are tidal, thermal, current and ocean/river waves and salinity gradient.

\section{Experimental Setup}

The testing tool used in this research was very simple and it used the material which is easy to find in the market, as shown in Figure 3 (a), with the dimension as shown in Figure 3 (b).
A wind tunnel is a device which is used to study the aerodynamics of airflow characteristics. Thus, using this apparatus can simulate the actual state of an object under the influence of aerodynamic forces in the field of aeronautics, to analyze the aeronautic flight mechanics performance. This research used the open circuit wind tunnel which located at Mercu Buana University, as shown in Figure 4.

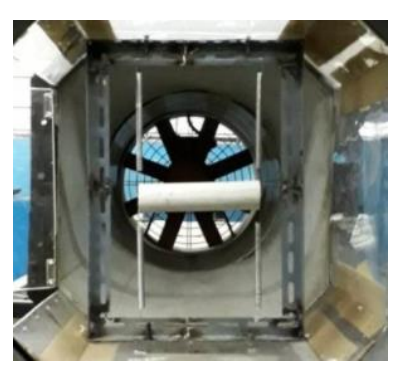

(a)

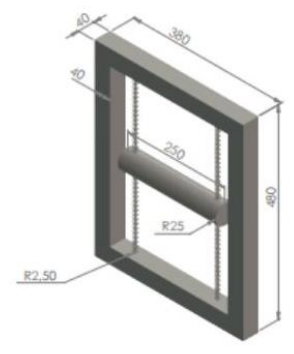

(b)
Fig. 3. The testing tool body

The beams are placed inside of the wind tunnel to avoid interference with the air flow. Vibration responses of the cylinder are measured by one laser displacement sensors.

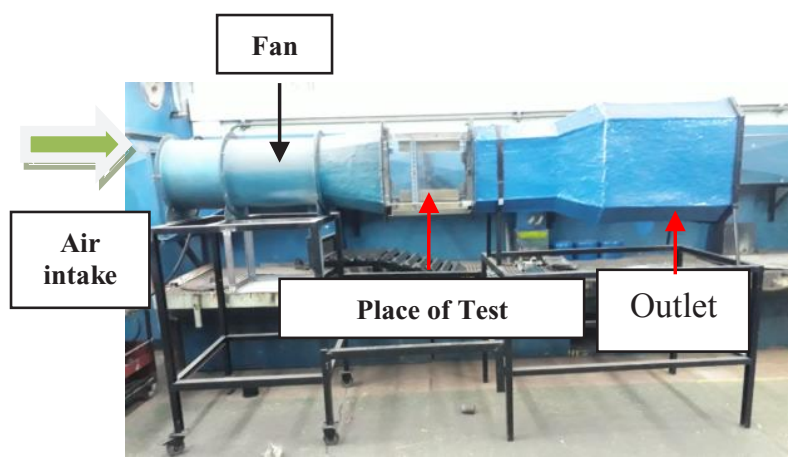

Fig. 4. Open circuit wind tunnel

The working principle of this type is that it straightly flows from the entering side to the outside area, and the air that enters the wind tunnel will be thrown away to the environment.

\subsection{The Wind Tunnel Parts}

In general, a wind tunnel consists of a fan, diffuser, test section, contraction, and settling chamber. The fan is the major part to produce air. The fan relates to a motor axle mover, so the fan can turn and produce air.

\subsubsection{Fan}

The fan which was used in this research was the one with axial flow. it is because this research used wind tunnel open circuit. As a result, the air flow which is parallel and in one line with drive motor shaft and does not require a guide casing. This axial flow fan can be controlled to turn so that it can produce wind with the speed that we want. Below is the specification of blower motor: 
- Power use is $1,1 \mathrm{~kW}$

- Fan Rotate is $2825 \mathrm{rpm}$

\subsubsection{Regulator or Inverter}

Regulator or inverter serves to adjust the rotation of the axial flow fan motor to produce a wind with the adjustable speed (Figure 5).

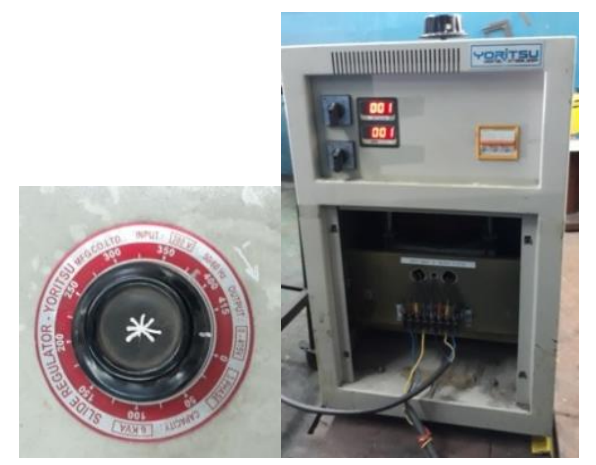

Fig. 5. Regulator

\subsubsection{Anemometer}

The major function of Anemometer is to measure the speed of the wind. This equipment can measure the speed of the wind (velocity) and the wind pressure. The Anemometer which was used in this research is as shown in Figure 6.

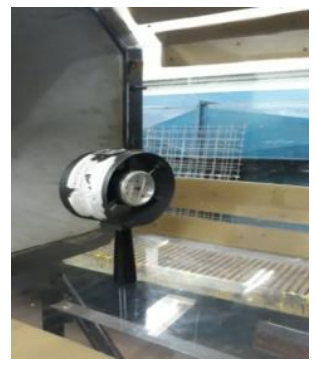

Fig. 6. Anemometer

\subsection{Cylinder}

This research used two polyvinyl chloride pipes with the same length $(\mathrm{L}=195 \mathrm{~mm})$ but different diameter as in Figure 7 and Table 1.

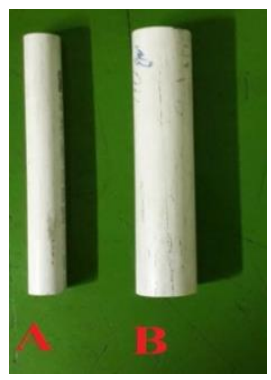

Figure 7. The Specimen of pipe PVC
Table 1. Specimen Data

\begin{tabular}{|c|c|c|c|}
\hline No & Specimen & Diameter $(\mathbf{m m})$ & Massa (kg) \\
\hline 1 & First Pipe (A) & 0.055 & 0.09 \\
\hline 2 & Second Pipe (B) & 0.06 & 0.11 \\
\hline
\end{tabular}

\section{The Model of The Flow-Induction Vibration for One Cylinder}

In the vibration system, the number of vibration responses that occur highly depends on the initial condition. In the actual state of the vibration system, it is so complex that the mathematically will be difficult to be analyzed. Therefore, in predicting the analysis, the system based on specific input conditions is made to allow us creating models, equations, and completion of mathematical vibration system analysis so that the vibration equation can be interpreted. The free-body diagram of the vibration system due to the flow of one cylinder on the PVC pipe material is made. The freebody diagram is shown in Fig. 8.

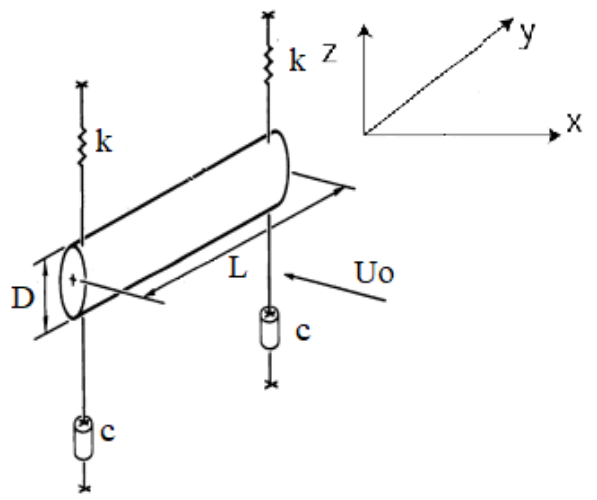

Fig. 8. Flow-velocity diagram on PVC pipe material [4]

From Figure 8, we can identify that the vibration characteristics of the cylinder will be affected by diameter of cylinder (D), length of cylinder (L), thus causing changes to the mass $(\mathrm{M})$ of the cylinder, while the oscillation frequency occurring in the absence of flow is $f_{s}^{0}$. Meanwhile, as flow velocity varies, we analyze the amplitude (A) and the main frequency in the motion spectrum of analysis. In Figure 8 The motion of the cylinder that leads transversely to the current is assumed to follow an oscillator, so it can be written to be

$$
M \ddot{z}+c \dot{z}+k z=F_{L}
$$

Where $\mathrm{k}$ is the spring stiffness, $\mathrm{N} / \mathrm{m}^{2}, \mathrm{M}$ is mass, $\mathrm{N}$, whereas $\mathrm{F}_{\mathrm{L}}$ is the lifting force acting on the $\mathrm{z}$-directional system, where $\mathrm{F}_{\mathrm{L}}[5]$ is

$$
F_{L}(t)=\frac{1}{2} \rho U_{o}^{2} D L C_{L}(t)
$$

where $\mathrm{U}_{\mathrm{o}}$ is the wind speed, $\mathrm{D}$ is the diameter of the cylinder, whereas $C_{L}$ is the variation of lift coefficients. 
Variation of lift coefficients is obtained by using the following equation

$$
C_{I_{L}}(t)=C_{I_{a}}^{0} \sin \left(2 \pi f_{\pi} t\right)
$$

Where $C_{T_{a}}^{0}=$ amplitude of elevator, usually uses a value of 0,3

$$
f_{s}=\frac{s_{t} U_{0}}{D} \text {, where } S_{t} \text { is a Strouhal number, }
$$

Because of the influence of $U_{0}$, there will be a force that fluctuates on the cylinder so that it will lift the cylinder up and down, so the lift coefficient is obtained due to the load from the fluctuating wake behind it, as shown in Figure 9.

The amount of wake produced depends on the influence of the Reynolds number. The Reynolds number is one of dimensionless and very important numbers in fluid mechanics and can be used like any other non-dimensional numbers.

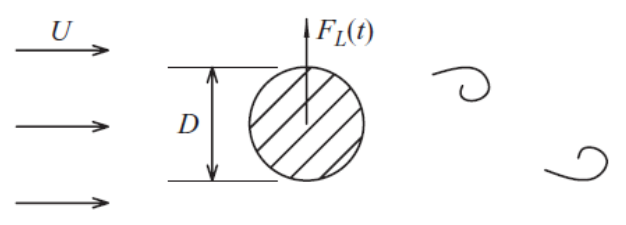

Fig. 9. The lift coefficient obtained by the load of the wake [5]

To give the criteria in determining dynamic similitude, if two flow patterns are geometrically similar, possibly with different fluids and different flow rates, they will have the value of the relevant dimensionless number and both are considered to have a dynamic similarity. Figure 10 shows the wake pattern generated by the effect of the Reynolds number.

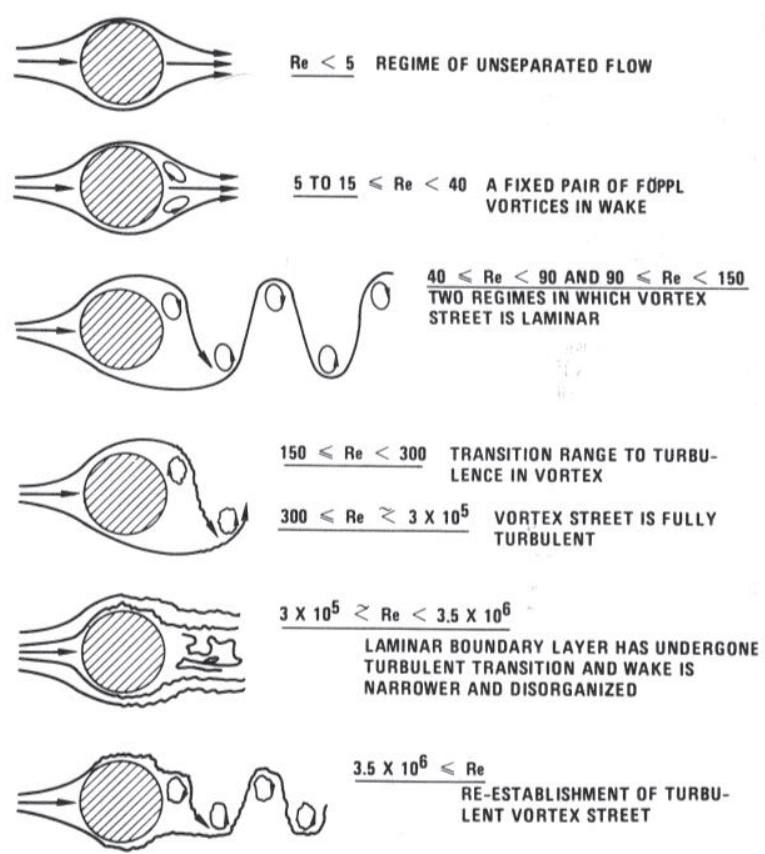

Fig. 10. Wake patterns affected by Reynold number [4]

\section{Results and Discussion}

\subsection{System Performance Benchmark}

Before doing the research, we did a simulation using COMSOL software. First, we will discuss the design and factors that affect the application of vibrations generated from the flow as an alternative energy. The flow which is getting faster will produce lock-in so that the vortex frequency approaching the private frequency system is formed. By using COMSOL, we would get the magnitude of the drag force and the elevator force that occurs in the cylinder mechanism. Figures 11 and 12 are the results of a COMSOL simulation on a cylinder supported by two elastic beams.

Figure 11 shows that the drag force that arises will rise rapidly to a certain extent, then the stationary or cylinder moves constantly even though the time is increasingly longer. This is, in contrast to the lift style which is the force that causes the cylinder to move horizontally where the lifting force does not change until close to 4 seconds. Then after 4 seconds, the lift force tends to rise and at 7 seconds upwards, the condition is stable (Figure 12).

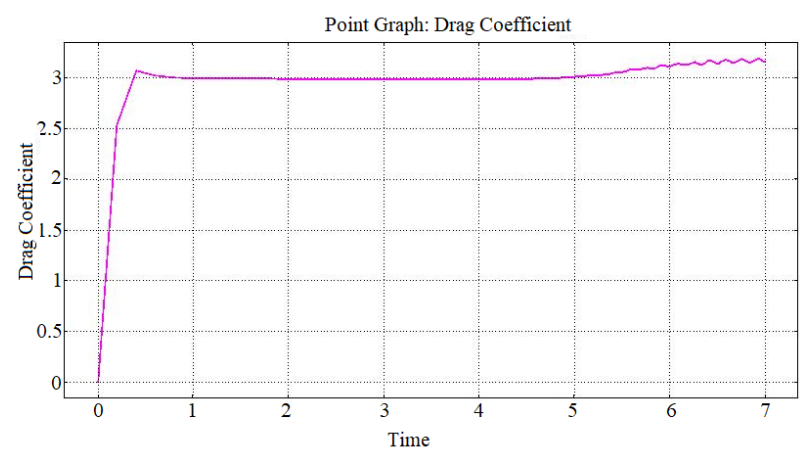

Fig. 11. Signals that occur due to the drag force on the cylinder which is sustained by to elastic beams.

Figure 12 shows the relationship between the flat flow velocity rate, private frequency and the diameter of the cylinder, so that will could get the speed reduction equation: $\mathrm{U}_{\mathrm{r}}=\mathrm{U} /\left(\mathrm{f}_{\mathrm{n}} \mathrm{D}\right)$.

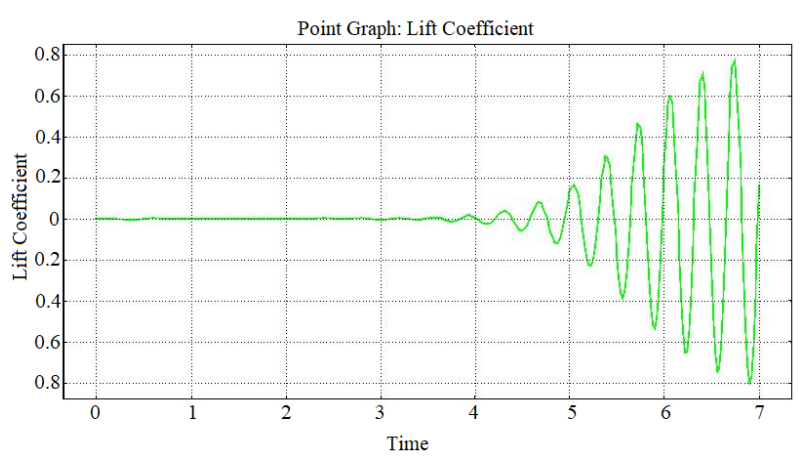

Fig. 12. The signal that occurs due to lift force on the cylinder was supported by two elastic beams.

The most important thing to note in designing this system is the effect of the ration of length to the diameter of the cylinder on the model to be. This is because that aspect will produce the Reynolds number effect which 
we want. Besides, the effect of the cylinder surface must be noted so that we can identify the wake and force generated by the cylinder due to the fluid flow, as desired. Figure 13 shows the wake flow produced from the COMSOL simulation.

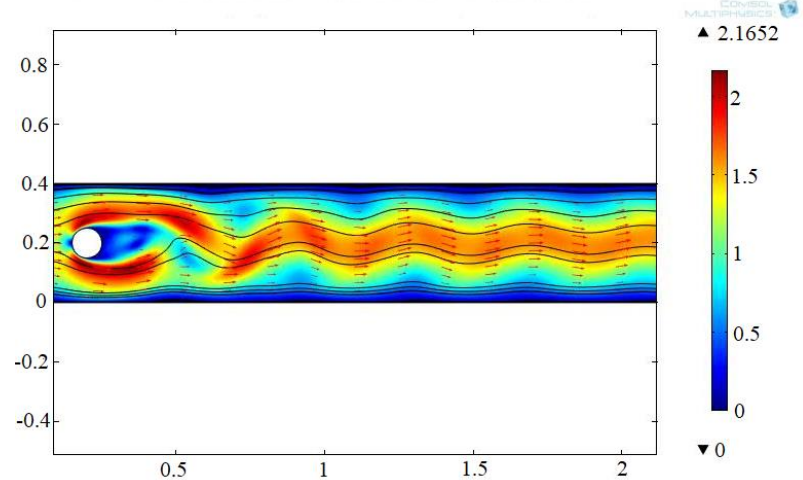

Fig. 13. COMSOL Simulation on a single cylinder

\subsection{Experiment Data}

In this paper, we used two pipes and three parameters wind velocities to know the lift of cylinder displacement. The velocity of the wind in this research is the normal Indonesian's wind speed. In this research, the fan in the wind tunnel was controlled, and then the wind velocity was measured by using an anemometer, and finally, we get the relationship between the voltage and the wind speed. Table 2 describes the relationship between the fan voltage and the speed of the wind which was generated.

Table 2. The effect of the wind velocity on the Volt in Wind tunnel

\begin{tabular}{|c|c|c|}
\hline No & Volt & The velocity of the Wind $(\mathrm{m} / \mathbf{s})$ \\
\hline 1 & 75 & 2.16 \\
\hline 2 & 100 & 3.26 \\
\hline 3 & 125 & 4.76 \\
\hline 4 & 150 & 6.33 \\
\hline 5 & 175 & 7.92 \\
\hline 6 & 200 & 9.7 \\
\hline
\end{tabular}

The experiment data is as shown in Table 3. To identify the effect of wind velocity on the lift displacement, we can see Figure 14. The first cylinder is placed in the equilibrium area which is supported by four springs, as can be seen in Figure 14.a. Then, the cylinder received a force from the wind with the velocity of 4.25 $\mathrm{m} / \mathrm{s}$. So, it will cause the cylinder to move up and down. This condition is called with a lift of displacement. The lift displacement which was obtained in this experiment was $7 \mathrm{~mm}$, as depicted in the following Figure 14.b.
Table 3. Experiment Data

\begin{tabular}{|c|c|c|c|}
\hline \multirow{2}{*}{ Lift of displacement $(\mathrm{mm})$} & \multicolumn{3}{|c|}{ Wind Velocity $(\mathrm{m} / \mathbf{s})$} \\
\cline { 2 - 4 } & 3.26 & 4.76 & 6.33 \\
\hline Pipe A (mm) & 2 & 5 & 10 \\
\hline Pipe B (mm) & 3 & 10 & - \\
\hline
\end{tabular}

The force vibration of the structure with air flow is measured to identify its dynamic property. Figure 15 shows the time history response of the displacement of the cylinder. It is shown that airflow caused by winds gradually rises to the maximum height that cylinders can produce due to flow.

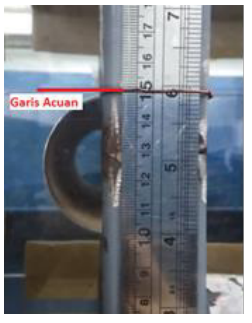

(a)

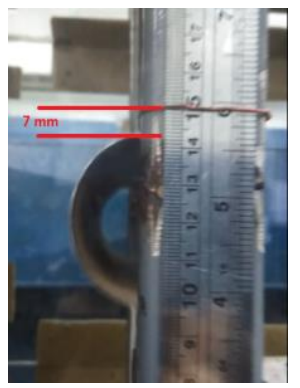

(b)
Fig. 14. Lift of displacement cylinder

In this paper, we used two types of pipes, with the same material but different diameter to determine the effect of wind velocity causing the cylinder to move toward lift direction. This paper will show only two cylinders with wind velocity parameters, as shown in Table 4

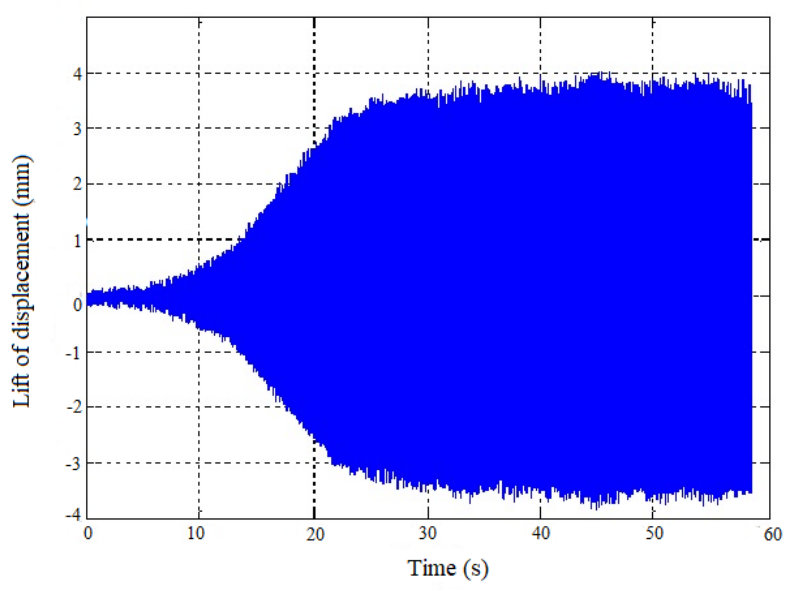

Fig. 15. Flow-induced vibration of the lift displacement cylinder in experiment

Based on this result, we will do a linear design generator which can generate electricity with displacement cylinder that has been produced. 
Table 4. The effect of velocity on lift displacement

\begin{tabular}{|c|c|c|c|}
\hline \multirow{2}{*}{ No } & $\begin{array}{c}\text { The diameter of } \\
\text { a cylinder }(\mathrm{m})\end{array}$ & $\begin{array}{c}\text { Wind velocity } \\
(\mathrm{m} / \mathrm{s})\end{array}$ & $\begin{array}{c}\text { Lift of } \\
\text { displacement } \\
(\mathrm{mm})\end{array}$ \\
\hline \hline \multirow{2}{*}{1} & \multirow{2}{*}{0.055} & $\mathrm{~V}_{1}=2.15 \mathrm{~m} / \mathrm{s}$ & $3-5 \mathrm{~mm}$ \\
\cline { 3 - 4 } 2 & & $\mathrm{~V}_{2}=3.2 \mathrm{~m} / \mathrm{s}$ & $4-6 \mathrm{~mm}$ \\
\cline { 3 - 4 } & \multirow{3}{*}{0.06} & $\mathrm{~V}_{3}=4.25 \mathrm{~m} / \mathrm{s}$ & $5-7 \mathrm{~mm}$ \\
\cline { 3 - 4 } & & $\mathrm{V}_{1}=2.15 \mathrm{~m} / \mathrm{s}$ & $2-3 \mathrm{~mm}$ \\
\cline { 3 - 4 } & & $\mathrm{V}_{2}=3.2 \mathrm{~m} / \mathrm{s}$ & $3-4 \mathrm{~mm}$ \\
\cline { 3 - 4 } & & $\mathrm{V}_{3}=4,25 \mathrm{~m} / \mathrm{s}$ & $4-5 \mathrm{~mm}$ \\
\hline
\end{tabular}

\section{Conclusions}

From this research, we drew some conclusions as follows:

1. In this experiment, we conducted a measurement of lift force resulted from vibration which occurred on PVC cylinder two kinds of specimens that are different in mass and diameter.

2. The best result for pipe B was obtained by setting the speed of $4.76 \mathrm{~m} / \mathrm{s}$, and the Lift displacement of 20 $\mathrm{mm}$.

3. The success of this experiment depends on the election and the success of the testing depends on the election of spring.

To produce the best lift force, we need to use the standard spring or four springs which have the constantans.

\section{References}

1. Daniel Rohni, http://fportfolio.petra.ac.id/user_files /97-030 /Makalah2Rohi-UK/20Petra.doc

2. Peraturan Presiden Republik Indonesia, Nomor $5 \mathrm{Th}$ 2006 Tentang Kebijakan Energi Nasional

3. Nurry, W.H, Dian, G.C, \& Kusriadie, Errie. Accessed from the website: http://litbang.esdm. go.id/images/stories/majalah_me_des_2012/des_201 2-pemetaan_potensi_energi_angin_indonesia.pdf (2012)

4. R.D. Blevins, Krieger Publishing Company (2001).

5. T. Nakamura, et al, Academic Press. Japan (2013).

6. P. W. Bearman, Annual Review of Fluid Mechanics. (16), pp: 195-222 (1984).

7. Bernitsas, Michael M., Raghavan, Kamaldev., BenSimon Y., Garcia E. M. H., Journal of Offshore Mechanics and Arctic Engineering. (130), pp: 20-30 (2008)

8. Griffin, O. M. and Koopmann, G.H, Journal of Sound and Vibration. (54), pp: 435-448 (1977).

9. Subekti, Yukinori, K., Yohei, H., and Takanori, E., ICROS-SICE International Joint Conference (2009).
10. T. Yuhei, Subekti, Yukinori, K., Yohei, H., Takanori, E., Dynamics and Design Conference (2009).

11. Subekti, The $8^{\text {th }}$ Hokkaido Indonesian Student Association scientific Meeting (2010).

12. C.H.K. Williamson, and Roshko, A., Journal of Fluids and Structures, pp: 355-381 (1988). 